Alaska Division of Geological \& Geophysical Surveys

RAW-DATA FILE 2011-3

Overview Report

\title{
HIGH-RESOLUTION LIDAR DATA FOR ALASKA INFRASTRUCTURE CORRIDORS
}

by T.D. Hubbard, R.D. Koehler, and R.A. Combellick

May 15, 2012

Deliveries 1-11

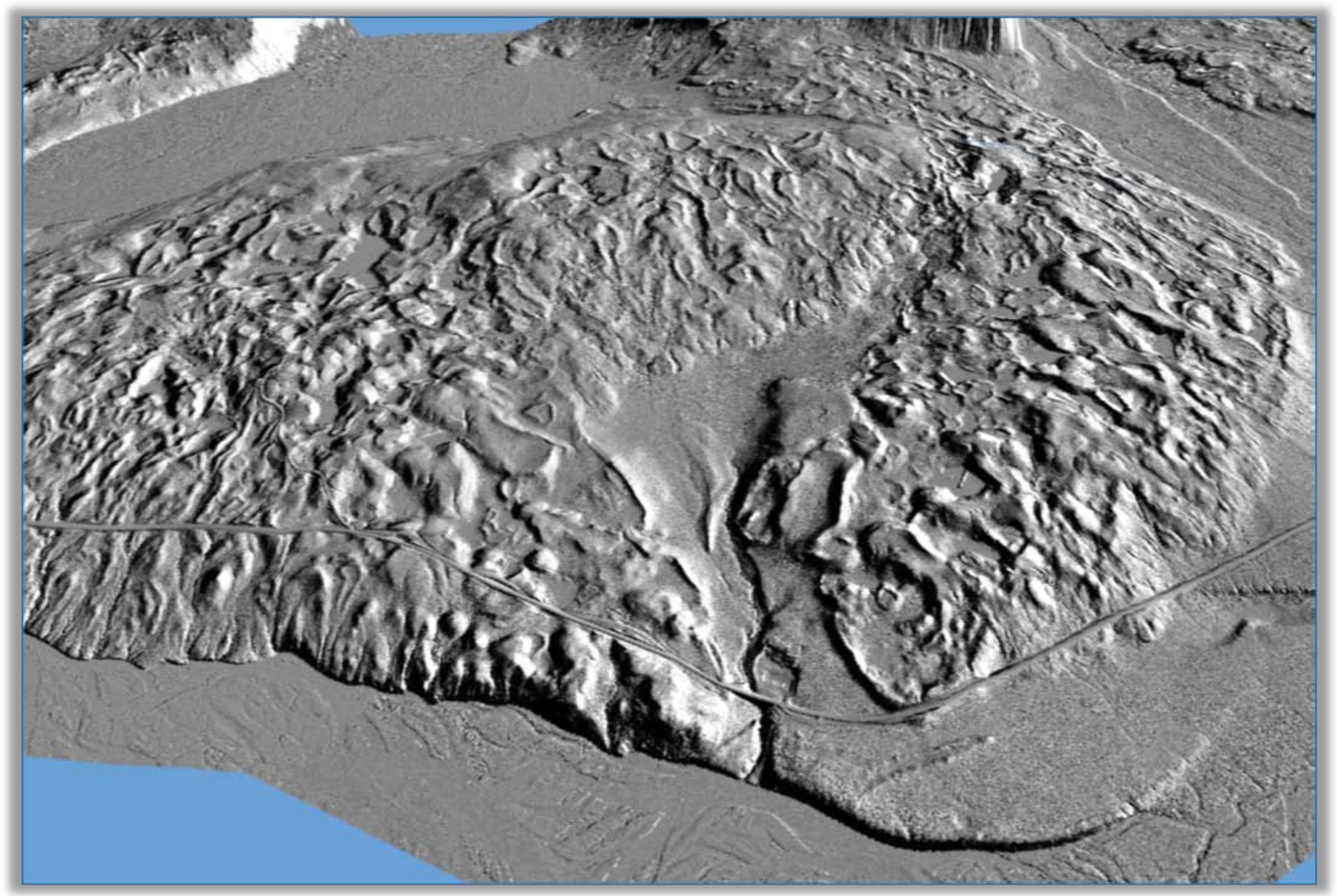

Oblique view to the southwest of a lidar hillshade image showing a Donnelly-age esker-kame complex between Johnson River and Little Gerstle River, Mt. Hayes Quadrangle. The Alaska Highway is in the foreground.

THIS REPORT HAS NOT BEEN REVIEWED FOR TECHNICAL CONTENT

OR FOR CONFORMITY TO THE EDITORIAL STANDARDS OF DGGS

Released by:

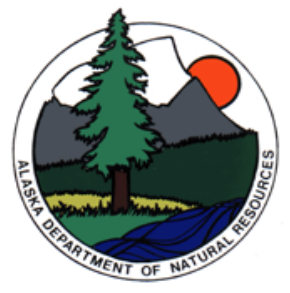

STATE OF ALASKA

DEPARTMENT OF NATURAL RESOURCES

Division of Geological \& Geophysical Surveys

3354 College Road F Fairbanks, Alaska 99709-3707

Email: dggspubs@alaska.gov

Website: www.dggs.alaska.gov

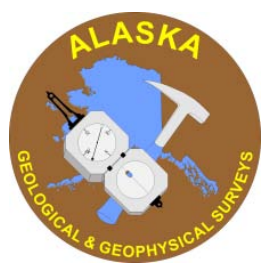




\section{CONTENTS}

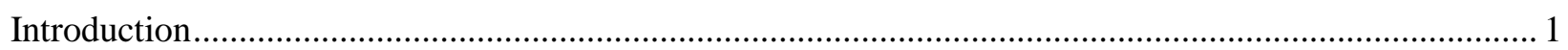

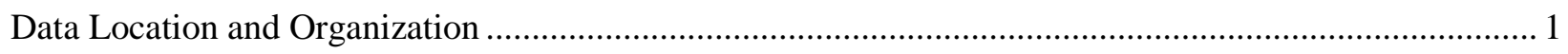

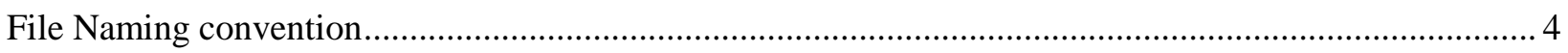

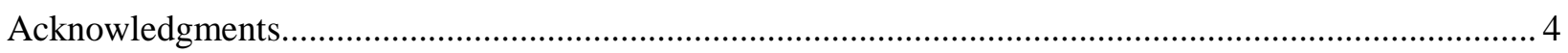

\section{Figures}

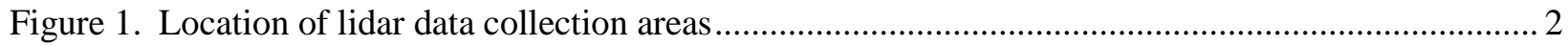

\section{Tables}

Table 1. USGS quadrangles associated with each lidar data delivery...................................................... 3

Table 2. Abbreviations used in file names to designate different data types ........................................... 4

Note: This report, including all digital lidar data, explanations, and tables, is available in digital format from the DGGS website (www.dggs.alaska.gov) for free download. 


\title{
HIGH-RESOLUTION LIDAR DATA FOR ALASKA INFRASTRUCTURE CORRIDORS
}

\author{
by T.D. Hubbard ${ }^{1}$, R.D. Koehler ${ }^{1}$, and R.A. Combellick ${ }^{1}$ \\ May 15, 2012 \\ Deliveries 1-11
}

\section{Introduction}

In advance of design, permitting, and construction of potential natural gas pipelines to deliver North Slope natural gas to out-of-state and Alaska customers, the Division of Geological \& Geophysical Surveys (DGGS) acquired, and is making publicly available, lidar (light detection and ranging) data for an area of $\sim 3,000$ square miles along the proposed pipeline routes. This data acquisition was supported by the Alaska Gas Pipeline Project Office, the Office of the Federal Coordinator, and the Alaska Gasline Development Corporation. These data serve multiple purposes, but were primarily collected to (1) evaluate active faulting, slope instability, thaw settlement, erosion, and other engineering constraints along the proposed pipeline routes, and (2) provide a base layer for the state-federal GIS database that will be used to evaluate permit applications and construction plans. Lidar has proven to be one of the most useful forms of remotely sensed data for identification and characterization of potentially active faults and many other surficial-geologic landforms and hazards, especially in areas of heavy vegetation where access may be difficult and other forms of remotely sensed data are ineffective.

\section{Data Location and Organization}

Lidar data, acquired and processed by Watershed Sciences, Inc. (WSI) consists of: (1) continuous 1-milewidth coverage over existing infrastructure along the entire length of the proposed natural gas pipeline corridors from Prudhoe Bay to the Canada border along the Trans-Alaska Pipeline System (TAPS) and Alaska Highway, from Delta Junction to Valdez along the TAPS, and Livengood to the Anchorage area along the George Parks Highway; (2) approximately 1-mile-wide corridors over routes the State believes gas pipeline applicants are considering, where departing from existing infrastructure; (3) half-mile-wide coverage of existing primary pipeline-support roads where outside the main corridor; and (4) expanded areas of coverage along these corridors where data are needed for evaluation of active faults, slope instability, and other hazards. Figure 1 (following page) shows the areas where lidar data were collected.

To facilitate processing and product delivery, WSI grouped the data into delivery areas (subsets of the entire data collection region) in the order in which they were processed, with files for each delivery area organized by 1:63,360-scale quadrangle(s). Following lidar data collection and processing by WSI and their survey subcontractor, McClintock Land Associates, WSI sent the data for each delivery area to the State of Oregon Department of Geology and Mineral Industries (DOGAMI) for independent quality control analysis. After addressing any concerns from DOGAMI, WSI sent the revised data set to DGGS along with a delivery report describing details about lidar acquisition, accuracy, and quality for the delivery area. DOGAMI also provided a separate report for each delivery area summarizing their methodologies and results of quality control checks.

Via its website at http://www.dggs.alaska.gov/pubs/id/22722, DGGS is making lidar data available to the public by USGS quadrangle in the order that delivery areas are received from WSI. A single data delivery

\footnotetext{
1 Alaska Division of Geological \& Geophysical Surveys, 3354 College Rd., Fairbanks, AK 99709-3707; trent.hubbard@alaska.gov
} 




Figure 1. Location of lidar data collection areas, shown by gray shading. More information and a map showing lidar delivery areas to date are available on the DGGS website (http://www.dggs.alaska.gov/pubs/id/22722). 
from WSI typically covers portions of several 1:250,000-scale quadrangles. Individual delivery reports from WSI are combined into a comprehensive report organized by delivery area. Section 1 of this delivery report contains information about the first delivery received by DGGS; Section 2 contains information about the second delivery received, and so on. A similarly organized quality control report contains information provided by DOGAMI. Both reports are available via the DGGS website and will be updated as additional data delivery areas are released. Table 1 lists the USGS 1:63,360-scale quadrangle areas associated with each section of the current comprehensive reports.

If you would like to be notified automatically when the data are updated or when new data are added to this project, please sign up for the DGGS news feed (available via email, RSS, Twitter, or Facebook) on the DGGS home page at http://www.dggs.alaska.gov/. 
DELIVERY 1

\begin{tabular}{|c|c|}
\hline Tanacross & Mt. Hayes \\
\hline tnxb6a & xmhb1 \\
\hline tnxc6a & xmhc1a \\
\hline $\operatorname{tn} x c 6 b$ & xmhc1b \\
\hline $\operatorname{tn} x c 6 c$ & xmhd1 \\
\hline $\operatorname{tn} x d 6$ & \\
\hline
\end{tabular}

\section{DELIVERY 2}

\begin{tabular}{|c|}
\hline Mt. Hayes \\
\hline xmhb4 \\
\hline xmhc2 \\
\hline xmhd2 \\
\hline xmhd3a \\
\hline xmhd3b \\
\hline xmhd4b \\
\hline
\end{tabular}

DELIVERY 3

\begin{tabular}{|c|c|}
\hline Nabesna & Tanacross \\
\hline nabd1 & tnxa2 \\
\hline nabd2 & tnxa3 \\
\hline & tnxb3 \\
\hline
\end{tabular}

DELIVERY 4

\begin{tabular}{|c|c|c|}
\hline Fairbanks & Big Delta & Big Delta \\
\hline faic1a & xbda4a & xbdb6b \\
\hline faic1b & xbda5 & xbdb6c \\
\hline & xbdb5a & xbdc6a \\
\hline & xbdb5b & xbdc6b \\
\hline & xbdb6a & xbdc6c \\
\hline
\end{tabular}

\section{DELIVERY 5}

\begin{tabular}{|c|c|c|}
\hline Bettles & Tyonek & Talkeetna \\
\hline beta1 & tyob1a & tala1 \\
\hline betb1 & tyob1b & talb1 \\
\hline betb2 & tyob2 & talc1 \\
\hline betc2 & tyoc1a & tald1 \\
\hline betd1 & tyoc1b & \\
\hline betd2 & tyoc2 & \\
\hline & tyod1 & \\
\hline
\end{tabular}

\begin{tabular}{|c|c|c|}
\hline Tanana & Wiseman & Anchorage \\
\hline tand1 & wisa1 & ancc8 \\
\hline & wisb1 & \\
\hline
\end{tabular}

\section{DELIVERY 6}

\begin{tabular}{|c|c|c|}
\hline Fairbanks & Livengood & Livengood \\
\hline faid1a & liva2 & livc4b \\
\hline faid1b & liva3 & livc5 \\
\hline faid1c & livb3 & livd5 \\
\hline faid1d & livb4a & livd6a \\
\hline faid2a & livc4a & livd6b \\
\hline
\end{tabular}

\section{DELIVERY 7}

\begin{tabular}{|c|c|}
\hline Fairbanks & Healy \\
\hline faia5 & heaa5 \\
\hline faib4 & heaa6 \\
\hline faib5 & heab4 \\
\hline faic4 & heab5a \\
\hline faic5 & heab5b \\
\hline faid2b & heac4 \\
\hline faid3a & heac5 \\
\hline faid3b & heac6 \\
\hline faid4a & head4 \\
\hline faid4b & head5 \\
\hline
\end{tabular}

\begin{tabular}{|c|c|}
\hline Livengood & Talkeetna Mts. \\
\hline liva4 & tImd6 \\
\hline livb4b & \\
\hline
\end{tabular}

\section{DELIVERY 8}

\begin{tabular}{|c|c|}
\hline Nabesna & Tanacross \\
\hline nabc1 & tnxb4 \\
\hline nabd1 & tnxb5a \\
\hline & tnxb5b \\
\hline & tnxb6a \\
\hline & tnxb6b \\
\hline
\end{tabular}

\section{DELIVERY 9}

\begin{tabular}{|c|c|c|}
\hline Gulkana & Mt. Hayes & Big Delta \\
\hline gulc3a & xmha3 & xbda4b \\
\hline gulc4a & xmha4 & \\
\hline gulc4b & xmhb4 & \\
\hline guld3 & xmhc4 & \\
\hline guld4a & xmhd4a & \\
\hline guld4b & & \\
\hline
\end{tabular}

Table 1. USGS quadrangles associated with each lidar data delivery. 
DELIVERY 10

\begin{tabular}{|c|c|}
\hline Gulkana & Valdez \\
\hline gula3 & vala4 \\
\hline gula4a & vala5 \\
\hline gula4b & vala6 \\
\hline gulb3a & vala7 \\
\hline gulb3b & valb3 \\
\hline gulb4 & valb4 \\
\hline gulc3b & valc4 \\
\hline gulc4c & vald4 \\
\hline
\end{tabular}

DELIVERY 11

\begin{tabular}{|c|c|c|c|c|}
\hline Chandalar & Philip Smith Mts. & Sagavanirktok & Wiseman & Beechey Point \\
\hline chnb6 & psma4 & saga3a & wisb1 & xbpa3 \\
\hline chnc6 & psma5 & saga3b & & xbpa4 \\
\hline chnd6 & psmb4 & saga3c & & xbpb3 \\
\hline & psmb5a & saga4 & & \\
\hline & psmb5b & sagb3 & & \\
\hline & psmc4 & sagc3 & & \\
\hline & psmc5 & sagd3a & & \\
\hline & psmd3a & sagd3b & & \\
\hline & psmd3b & sagd4 & & \\
\hline & psmd4 & & & \\
\hline
\end{tabular}

Table 1. USGS quadrangles associated with each lidar data delivery.

The DGGS data release includes bare-earth digital elevation models (DEMs), lidar intensity images, bareearth DEM hillshade images, water body polygons, canopy cover digital surface models (DSMs), normalized DSMs, vegetation DSMs, highest-hit DSMs, and Coefficient Variation DSMs. Other lidar data, including point cloud data, will be made available at a later time.

\section{File Naming Convention}

Download packages are organized by U.S. Geological Survey (USGS) 1:250,000-scale quadrangle. Each 1:250,000-scale quadrangle download package will have data for one or more of the associated 1:63,360scale quadrangles. The names of geospatial data files (tiles) in each download package identify both the lidar data type and 1:63,360-scale quadrangle location of the data. The first five characters of each file name correspond to the abbreviated quadrangle name associated with the USGS 1:63,360-scale quadrangle map. If quadrangles contain two or more tiles, they were split into two portions in order to 
create a more manageable file size, and an "a”, "b”, “c”, or “d” was added to the end of the name. Table 2 lists the abbreviations used for each available data type. Quadrangle abbreviations follow USGS standards (see Table 1 for examples).

\begin{tabular}{|l|c|}
\hline \multicolumn{1}{|c|}{ Data type } & Data type abbreviation (x) \\
\hline Bare-earth digital DEM & be \\
\hline Bare-earth DEM hillshade image & hs \\
\hline Lidar intensity image & in \\
\hline Hydro-flattened water bodies & lakes \\
\hline Canopy cover DSM & cc \\
\hline Normalized DSM & nDSM \\
\hline Vegetation DSM & veg \\
\hline Highest-Hit DSM & hh \\
\hline Coefficient Variation DSM & $\mathrm{cv}$ \\
\hline
\end{tabular}

Table 2. Abbreviations used in file names to designate different data types. This table will be updated as additional products become available.

File naming examples:

1. A file with the name "be_xmhb4" is a bare-earth DEM for the Mount Hayes B-4 Quadrangle.

2. A file with the name "be_tnxb6a" is one of several tiles of bare-earth DEM data for the Tanacross B-6 Quadrangle.

\section{Acknowledgments}

The authors are thankful for support from several staff members of the Division of Geological \& Geophysical Surveys. Jim Weakland helped process and interpret the data; Susan Seitz created the programming by which the data is offered online; Simone Montayne assisted with metadata creation and helped streamline the process for its update; and Ken Woods managed data on the server, and ensured there was plenty of room for the huge amount of data. 